\title{
INTELLIGENT QUERYING FOR ADAPTIVE COURSE PREPARATION AND DELIVERY IN E-LEARNING
}

\author{
Reem Al-Otaibi and Shehab Gamalel-Din \\ Faculty of Computing and Information Technology, King Abdul-Aziz University \\ Jeddah, Saudi Arabia \\ Email: ralotibi@kau.edu.sa,drshehabg@yahoo.com
}

\begin{abstract}
Today many open sources of information are available on the Internet that provide sharing and reusing of learning materials to reduce the cost of designing new courses, save the time, and avoid effort duplication. In this research, mechanisms that support instructors and e-tutors in selecting the most appropriate learning materials for more effective learning outcomes are investigated. On one hand, instructors need to prepare course materials that meet specific goals such as course objectives and syllabus. On the other hand, students need to have studying materials that match their learning styles and that are built based on their background knowledge. Therefore, the objective of the research is to build a model and an architecture for a Smart e-Learning Assistant (SeLA) that provides instructors and e-tutors with smart assistance in selecting the most appropriate Learning Objects (LOs) for both Adaptive Course Preparation and Delivery from a higher level perspective. SeLA employs two main theories in building its model: the Revised Bloom's Taxonomy of instructional design (RBT) and Felder-Silverman Learning Style Model (FSLSM). Under this research, a prototype in .NET environment has been developed and evaluated.
\end{abstract}

\section{KEY WORDS}

Bloom's Taxonomy, Learning Style, Student Model, Adaptive e-Learning, Learning Objects and Objectives Rewriting

\section{Introduction}

In the era of the Internet, open sources of information exist intensively in a way that made different types of materials particularly learning materials became abundant with the graceful permission of sharing and reusing them. As a result, instructors can use such learning materials in preparing their courses. The querying of LOs is based on the proper identification of the appropriate values of metadata attributes that specify the required material. As instructors differ in their objectives and perspectives, students, the course recipients, also differ in their skills, backgrounds, and learning styles. Thus, querying of learning materials is not as simple as it might appear.
Before going into the LOs retrieval process, it is essential to take into consideration some parameters such as the instructor's model including his/her teaching style and objectives, and the student's model including his/her previous knowledge and learning styles.

This research vision of querying LOs from repositories is shown in Figure 1. The researchers envision querying LOs as a more complex process than most current researches are considering. They believe that it is not such a naive process that requests objects simply by specifying the appropriate metadata. But rather it has to include other important parameters like the course objectives, teaching style, student learning style and other cognitive, pedagogical, and educational issues. In other words, LO querying process should be consider from a higher perspective, especially that course authors are mostly academicians who are mostly less knowledgeable in such issues like educational theories, instructional design backgrounds, and psychology and cognition theories.

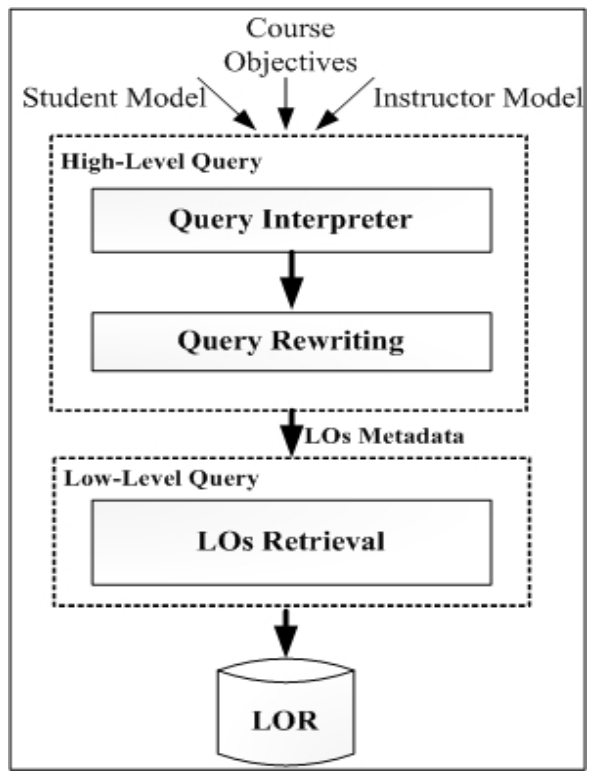

Figure 1. LOs Querying Levels 
This research is founded on two main assumptions that are believed to be valid in most communities. The first assumption is that many academic authors have not studied instructional design theories; hence, they are not skilful enough to properly state their course objectives and design their courses accordingly to meet those objectives. Second, it is noticed that unskilled tutors usually have difficulties adapting their teaching approaches and methods to suit their students learning profiles. Selecting the appropriate learning materials that most suit the course objectives as well as the learner's model is an uneasy task for unskilled instructors. Thus, instructors and e-tutors assistance would be appreciated. For all these reasons, the idea of this research came in which designed a Smart e-Learning Assistant (SeLA) framework that intelligently:

- Assists instructors in preparing their courses in a way that allows them to ask their queries from a higher-level perspective by specifying their objectives and other requirements, and while they do so, SeLA assists them in selecting the most appropriate course materials.

- Delivers the adaptive courses according to each individual student's model (considering background knowledge and learning style).

This paper is structured as follows: Section 2 sheds some light on some relevant background. Section 3 gives an overview of the model, while Section 4 describes the general framework depicting how the learning style and the instructional design theories are incorporated in the selection of LOs. Section 5 describes the process of design and implementation the prototype to prove the concept and Section 6 illustrates the evaluation methods and discusses the results. Finally, Section 7 concludes by discussing the contributions of this research and highlighting potential areas for future work.

\section{Research Background}

When designing adaptive course, it is important to accommodate elements that reflect individual differences in learning. In this research, two theories have been employed: an instructional design theory and a learning style theory.

Many instructional design theorists used to design of instruction. Bloom's taxonomy is widely used to classify curriculum and instructional objectives. Bloom's Taxonomy [1] divides educational objectives into three "domains:” Cognitive (Knowledge), Psychomotor (Skills) and Affective (Attitude). Domains can be thought of as categories. Each of these domains is organized as a series of levels or pre-requisites starting from the simplest to the most complex.

Cognitive (knowledge) domain, the most used of the three domains, refers to knowledge structures. Bloom [1] defined six major categories for the cognitive domain, which are listed from the simplest to the most complex as follows: Knowledge, Comprehension, Application, Analysis, Synthesis, and Evaluation. These categories can be thought of as degrees of difficulties. That is, the first one must be mastered before the next one. Bloom also suggested for each category's keywords that can be used in defining course objectives, such as defines, describes, and identifies for the knowledge category and comprehends, distinguishes, explains, and gives Examples for the comprehension category etc.

Anderson and his colleagues [2] have made some modifications to the knowledge domain. The names of the six major categories were changed from noun to verb forms. Knowledge, Comprehension and Synthesis in Bloom's model were re-titled to Remembering, Understanding and Creating. Evaluation moved from the top to Evaluating in the second from the top, Synthesis moved from second on top to the top as Creating.

A second theory that has been employed is a learning style theory. The impact of learning styles on student achievement appears to be much researched. The underlying idea of a learning style approach is that a person learns more effectively when information is presented in a manner that matches his/her preferred methods of acquiring and processing information. There are many theories in that concern; however, FSLSM has been chosen $[3,4]$ because of the following reasons:

- It combines several major learning style models. Each of the four dimensions of FSLSM (active/reflective, sensing/intuitive, visual/verbal, and sequential/global) is influenced by other learning style models for example the learning style model by Kolb [5] and the Myers-Briggs Type Indicator [6].

- FSLSM dimensions are not new but the way in which they are combined and how they relate to the learning styles of students can be seen as new [7].

FSLSM incorporates four dimensions, the perception dimension (sensing/intuitive), the processing dimension (active/reflective), the input dimension (visual/verbal) and the understanding dimension (sequential/global). Each student has a preference on each of the dimensions, student's learning style could be one of the $16\left(2^{4}\right)$ learning styles in the FSLSM (one, for example, is the sensing/ visual /active/sequential).

\section{Intuitive Understanding of SeLA Model}

Figure 2 depicts the general model of SeLA. It goes through two phases: Authoring and Delivery. First, the Smart Instructor Assistant component of SeLA would refine the objectives through several steps of rewritings so as to align them with the revised Bloom's taxonomy [2] producing a pool of LOs suitable for all expected student 
models. Second, the Smart e-Tutor at delivery time would choose those LOs that most suit each individual student out of this LOs pool according to his/her learning styles and background knowledge.

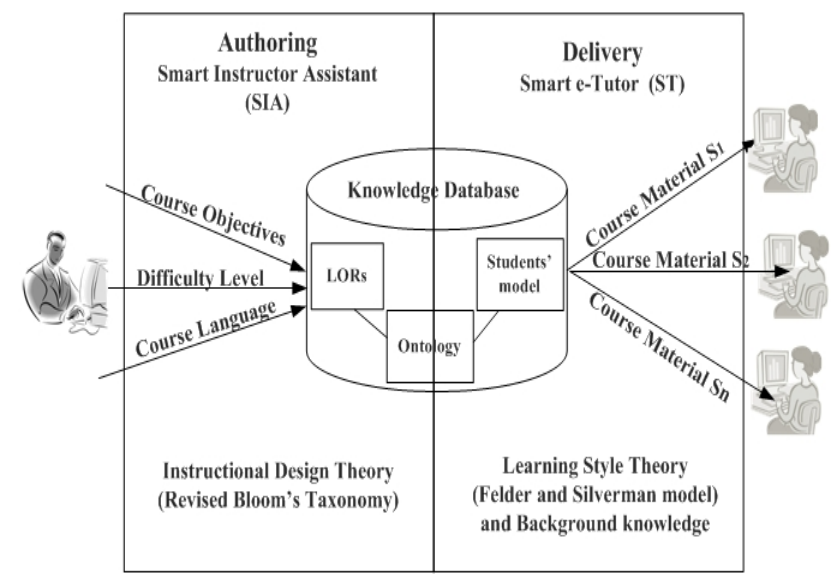

Figure 2. General Model of SeLA

\subsection{The Authoring Phase}

The Authoring Engine is activated during course preparation by the instructor. It receives the general instructor's objectives and other requirements and produces the detailed syllabus. The basic functions of this engine are:

1. Rewrite the instructor' objectives to produce the instructional objectives,

2. Identify the detailed course topics according to the instructional objectives,

3. Select the learning materials that fulfill these topics.

It receives the general instructor's objectives and then applies the RBT employing a specially designed ontology that specifies the relationships among the concepts. SeLA's model suggests four relationships between the concepts: has part, prerequisite, follow and related relations. Each concept in the domain ontology has an attribute that identifies its difficulty level, it could be \{Fundamental, Intermediate, Advanced\}.

\subsubsection{Objectives Rewriting}

Objectives rewriting employs three categories of rewriting rules that are applied in sequence to rewrite the objectives [8]:

- Category\#1: Rewriting rules based on the domain ontology of concepts and relations (has_parts and follow).

- Category\#2: Rewriting rules based on the domain ontology and course prerequisite requirements.

- Category\#3: Rewriting rules based on RBT and prerequisite within the same concept.
The difference between the second and third categories is that category\#2 focuses on the prerequisite relationship between the different concepts such as Concept $Y$ is prerequisite for Concept $X$. On the other hand, category\#3 focuses on the prerequisite relationship between the different levels of the same concepts. These levels are classified according to RBT, i.e., applying Concept $X$ requires understanding Concept $X$.

\subsubsection{Topic Elements Selecting}

To select the matching topic elements, this research follows some recommendation from the literature. Firstly, according to Nussbaumer, Gütl and Albert [9]:

- The learning material that teaches the level "Remembering" should be a list of short statements, which indicates that this material teaches a skill of the remember category.

- The learning material with a long text combined with an animated graphics is an indication that this material teaches a skill of the "Understanding" category.

- The third level "Applying” consists of a step-by-step explanation.

Secondly, according to the classification that is suggested by Zouaq, Nkambou and Frasson [10]. Each level in Bloom's taxonomy is matched with the most probable asset categories. For example, in order to define a concept (which is the Knowledge level of Bloom's Taxonomy), then an Introduction and a Definition about the concept must be provided.

For SeLA to achieve its work, this research made Zouaq's classification of assets as its basis for LO's categorization to match the RBT (see Figure 3). This research has adopted only the first three levels of the RBT.

\subsubsection{LOs Selecting}

In this step, SeLA retrieves the LOs from repositories that match the suggested topics taking into account all different student models. These LOs will be in different formats such as text, images and video, and in different instructional role such as example, theory and explanation.

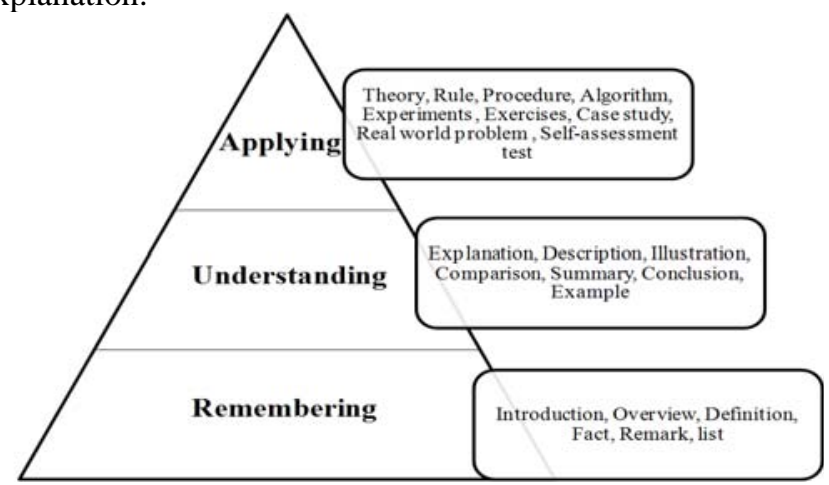

Figure 3. Suggested Correlations between RBT and Learning Materials 


\subsection{The Delivery Phase}

The Delivery Engine, which is activated during the course delivery to students, utilizes the given student model to identify both the preferred learning style and the background knowledge for each individual student. This phase begins with the suggested detailed syllabus that results from the authoring phase and utilizes the student model of each student to adapt course presentation and sequencing which can be described as follows:

1. Firstly, the background knowledge determines the actual syllabus to be covered and, hence, rewrites the syllabus to add any missing backgrounds at the appropriate level of knowledge.

2. Secondly, the student's learning style is utilized to properly select and organize the presentation of the educational materials.

\section{Conceptual Model of SeLA}

Figure 4 depicts the high-level conceptual model for SeLA.

The course objectives that are received by the Authoring Engine go through several steps of manipulation according to the instructor's model and other course requirements, such as, objectives, language and difficulty level. First, the Objectives Rewriting Module analyzes these input objectives and goes through a series of rewriting processes. Second, the Detailed Topics Identification Module selects the appropriate detailed topics that cover these objectives.
Third, the LOs Retrieving Module would then select the appropriate LOs from the LORs with the aid of the general domain ontology. The output of this phase is the "course repository" which is usually a collection of course specific LOs and prerequisite LOs that might be needed to cover missing background concepts for some students. The Authoring Engine also produces a course specific ontology - subset of the general ontology - that will be consulted later by the Delivery Engine when selecting the appropriate LOs that match a specific student's profile.

Centered on each individual student profile, the Delivery Engine chooses the appropriate LOs to be delivered to each specific student together with the most suitable presentation strategy. Doing so, the Delivery Engine goes through a process of three steps. First, the Learning Style Checking Module would determine the learning style for each student by providing a questionnaire for the student to answer. Second, the Background Checking Module checks the student's background by consulting the prespecified current student knowledge, and then adds any missing background by merging both the course specific LOs and the prerequisite LOs. Third, the Course Delivery Setup Module would identify the chosen objectives and its LOs according to the delivery objectives. Finally, those selected LOs are then passed to the Course Delivery Planning Module that would select the LOs that best match each individual student's preferred learning style and then orders them in an instructional strategy matching this specific student's model.

The following sub-sections will explain in detail some SeLA's components.

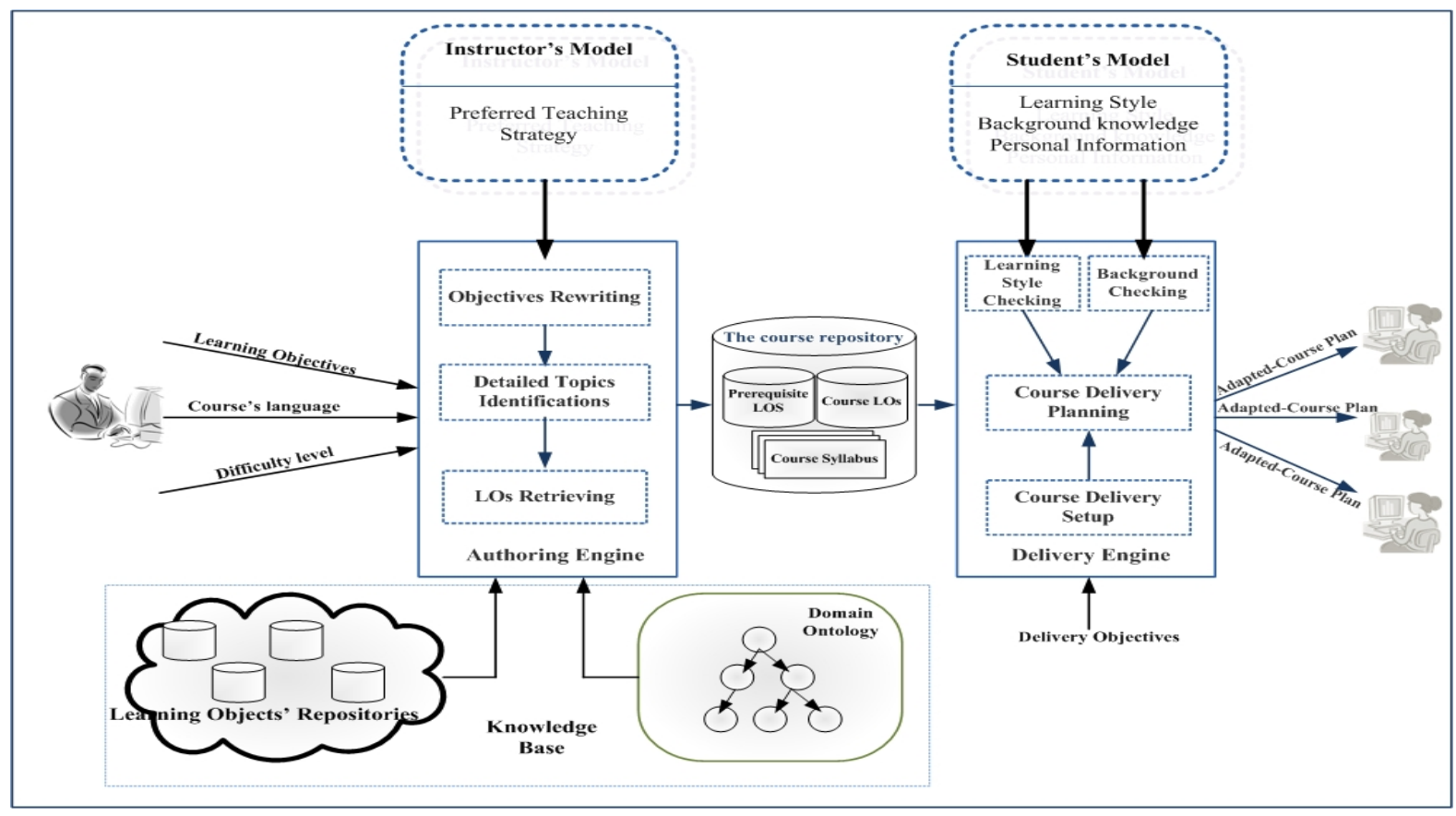

Figure 4. SeLA's Conceptual Model 


\subsection{Knowledge Base Representation}

The knowledge base of a course consists of two main parts: concepts domain ontology and the learning objects repository:

\subsubsection{The Concepts Domain Ontology}

It consists of concepts and relationships among them. Figure 5 depicts an abstract example of domain concepts' ontology in which concepts are interconnected by a set of semantic relationships. Four relations are suggested among domain concepts:

- HP (Has Part): X $\left(\mathrm{Y}_{1}, \mathrm{Y}_{2}, \ldots . \mathrm{Y}_{\mathrm{n}}\right)$ means that, the concept $\mathrm{X}$ is composed of the concepts $\mathrm{Y}_{1}, \mathrm{Y}_{2}, \ldots$, $Y_{n}$. It is interpreted as "to teach $X$ it is necessary to teach $\mathrm{Y}_{1}, \mathrm{Y}_{2}, \ldots$, and $\mathrm{Y}_{\mathrm{n}}$ ”. This relation is employed in rewriting Rule\#1.

- $\quad \mathrm{F}$ (Follow): F (X, Y) means that it is preferable to teach $\mathrm{X}$ and $\mathrm{Y}$ in this order. This relation supports the ordering of the objectives during rewriting.

- $\quad \mathrm{R}$ (Related): R (X, Y) means that, the concepts X and $\mathrm{Y}$ are related.

- $\quad$ P (Prerequisite): P (X, Y) means that, the concept $\mathrm{Y}$ requires the concept $\mathrm{X}$, i.e., before you can teach $\mathrm{X}$, you need to assure that $\mathrm{Y}$ is already taught. This relation supports rewriting Rule\#2 and helps in ordering LOs.

In order to support Rule\#3, the "Prerequisite" relation is enhanced by adding the first three cognitive levels of the RBT of educational objectives [2], which are Remembering, Understanding, and Applying (see Figure $5 \mathrm{~B}$ ). Saying that concept $\mathrm{Y}$ requires concept $\mathrm{X}$, we must also specify at which cognitive level. The following are the three suggested relations for the enhanced "Prerequisite" relation:

- Remembering_Prerequisite,

- Understanding_Prerequisite,

- Applying_Prerequisite,

In addition, adding a property for each concept in the ontology model is suggested to identify the level of difficulty, e.g. fundamental, intermediate, or advanced, in order to help in selecting the concept and the level of details according to the difficulty level was entered by the instructor.

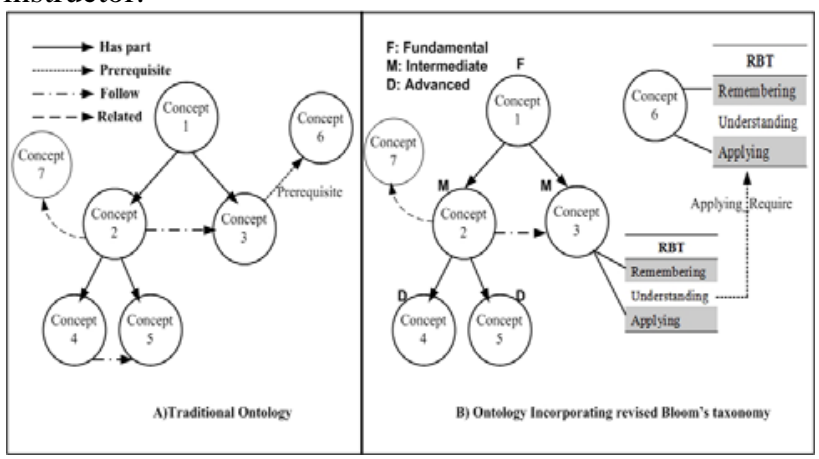

Figure 5. Abstract Example of Domain Concepts' Ontology

\subsubsection{The Learning Objects Repository}

It contains the learning objects and its necessary metadata for SeLA to achieve its objectives. Some extra attributes is suggested to the LO's specification standard as shown in Table 1.

Table 1. LO's Metadata Attributes as used by SeLA

\begin{tabular}{|c|c|c|}
\hline Metadata & Description & Values \\
\hline ID & $\begin{array}{l}\text { Identification } \\
\text { of LO }\end{array}$ & - \\
\hline Title & Title of LO & - \\
\hline Concept & $\begin{array}{l}\text { Concept } \\
\text { covered by this } \\
\text { LO }\end{array}$ & - \\
\hline Language & $\begin{array}{l}\text { The Language } \\
\text { that is used } \\
\text { within this LO }\end{array}$ & \{English, Arabic, French\}. \\
\hline $\begin{array}{l}\text { Technical } \\
\text { format }\end{array}$ & $\begin{array}{l}\text { Technical data } \\
\text { type for LO }\end{array}$ & $\begin{array}{l}\text { \{Pictures, Graphs, Images, Diagrams, } \\
\text { Flowcharts, Schematics, Concepts } \\
\text { maps, Animation, Video, Audio, } \\
\text { Schematics, Text, Highlighted text, } \\
\text { Hypertext }\} \text {. }\end{array}$ \\
\hline $\begin{array}{l}\text { Instructional } \\
\text { role }\end{array}$ & $\begin{array}{l}\text { Specific kind } \\
\text { of LO }\end{array}$ & $\begin{array}{l}\text { \{Introduction, Overview, Definition, } \\
\text { Fact, Remark, Example, Explanation, } \\
\text { Description, } \\
\text { Comparison, Summary, Conclusion, } \\
\text { Theory, Rule, Formula, Procedure, } \\
\text { Algorithm, Exercises, Case study, } \\
\text { Real world problem, Question , } \\
\text { AnswerToQuestion\}. }\end{array}$ \\
\hline $\begin{array}{l}\text { Cognitive } \\
\text { level }\end{array}$ & $\begin{array}{l}\text { That is covered } \\
\text { by this LO } \\
\text { according to } \\
\text { RBT }\end{array}$ & $\begin{array}{l}\text { \{Remembering, } \\
\text { applying }\}\end{array}$ \\
\hline Content type & $\begin{array}{l}\text { Type of } \\
\text { concept }\end{array}$ & \{Concrete, Abstract $\}$. \\
\hline $\begin{array}{l}\text { Teaching } \\
\text { Strategy }\end{array}$ & $\begin{array}{l}\text { Teaching } \\
\text { strategy used } \\
\text { within the LO }\end{array}$ & $\begin{array}{l}\text { \{Expository Explanation, Inquisitor } \\
\text { Explanation, Assessment\}. }\end{array}$ \\
\hline
\end{tabular}

\subsection{The Course Adaptation Process}

SeLA adaptively prepares courses according to the instructor's model and his/her objectives and adaptively delivers courses according to the student's model including learning style and previous knowledge.

This section discusses how the course's syllabus and LOs are selected to accommodate RBT in the Authoring phase and respectively, demonstrate how the Delivery phase adapts the course according to student's background knowledge and preferred learning style.

\subsubsection{Accommodating RBT}

The suggested model uses the learning objectives to find the matching topics and learning materials. To facilitate this process, each objective is expressed in a simple sentence having an action verb and a concept. For instance, a learning objective should not be just "search methods", but something like "explain search methods" or "implement search methods". This will allow authors to specify the content of a learning material more accurately. 
Fortunately, this structure would also make it easy to build a visual interface through which the user describes the objectives visually which supports this research assumptions about native instructors who do not have sufficient knowledge about writing correct objectives based on educational theories such as RBT.

To accommodate RBT, the learning objects are classified into three categories: remembering LOs, understanding LOs and applying LOs. Table 2 shows one possible suggested matching between RBT's First Three Levels and LOs. The LO's selection process depends mainly on what is the action and what is the concept. Based on the action component, the corresponding level is identified. For example, the following learning objective:

\section{Student be able to define depth first search algorithm \\ - The action is "define" \\ - The concept is "depth first search strategy"}

Using Table 2 , The define is in "Remembering" level for this reason the best learning material that satisfies this objective is "Definition".

Table 2. One Possible Suggested Matching between RBT's First Three Levels, its keywords and LOs

\begin{tabular}{|l|l|l|}
\hline Cognitive level & Action verb & LOs \\
\hline \multirow{4}{*}{ Remembering } & Remember & $\begin{array}{l}\text { Introduction, Overview, } \\
\text { Definition, Fact, Remark, List. }\end{array}$ \\
\cline { 2 - 3 } & Introduce & Introduction, Overview \\
\cline { 2 - 3 } & $\begin{array}{l}\text { Define, } \\
\text { Identify }\end{array}$ & Definition \\
\cline { 2 - 3 } Understanding & List , name & list \\
\hline \multirow{5}{*}{ Understand } & $\begin{array}{l}\text { Explanation, Description, } \\
\text { Illustration, Example, } \\
\text { Comparison, Summary, } \\
\text { Conclusion. }\end{array}$ \\
\cline { 2 - 3 } & Explain & Explanation \\
\cline { 2 - 3 } & Describe & Description \\
\cline { 2 - 3 } & Illustrate & Illustration \\
\cline { 2 - 3 } Applying example & Compare & Examples \\
\cline { 2 - 3 } & Summarize & Summarison \\
\cline { 2 - 3 } & Conclude & Conclusion \\
\hline & Apply & $\begin{array}{l}\text { Algorithm, Procedure, Theory, } \\
\text { Rule, Exercise, Case study, Real } \\
\text { world problem, Experiment, Self- } \\
\text { assessment test. }\end{array}$ \\
\cline { 2 - 3 } & $\begin{array}{l}\text { Solve, } \\
\text { compute, } \\
\text { calculate, use }\end{array}$ & $\begin{array}{l}\text { Exercise, Case study , Real world } \\
\text { problem, Self-assessment test }\end{array}$ \\
\hline
\end{tabular}

\subsubsection{Accommodating Background Knowledge}

The knowledge of different students on the concept being taught can vary greatly (different knowledge backgrounds). Therefore, SeLA utilizes the course syllabus that is produced from the authoring phase and rewrites the syllabus according to student's background knowledge as follows:

- Add any missing backgrounds at the appropriate level of knowledge,
- Remove the syllabus that is already studied by the student.

Accordingly, this research introduced a new type of LOs (Recall_LO). This LO is added as part of the domain ontology gives an overview about a concept and is linked to other concepts via the prerequisite link.

\subsubsection{Accommodating FSLSM}

This research adopted some of the recommendations in the literature to accommodate FSLSM [11, 12, 13, 14, 15]. An overview on the dimensions of FSLSM and their corresponding implications in pedagogy is summarized in Table 3.

Table 3. Recommendations for implications of FSLSM in pedagogy

\begin{tabular}{|c|c|}
\hline LS Dimension & LO Type and Selection Strategy \\
\hline Visual & $\begin{array}{l}\text { Pictures, Graphs, Diagrams, Flowcharts, } \\
\text { Schematics, Concepts maps, Animation, Video, } \\
\text { Schematics and Highlighted text. }\end{array}$ \\
\hline Verbal & Text, Hypertext, and Audio. \\
\hline Sensing & 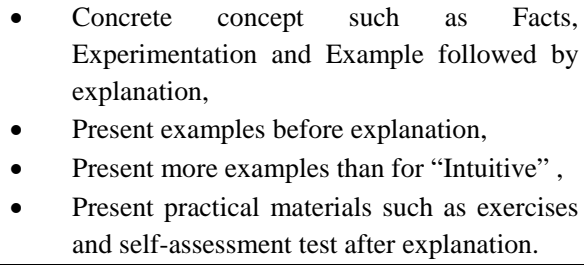 \\
\hline Intuitive & $\begin{array}{l}\text { - } \quad \text { Abstract concept such as Theory, Principle } \\
\text {,Explanation, and Mathematical formulas, } \\
\text { - } \quad \text { Present explanation and then examples, } \\
\text { - } \quad \text { Present practical materials such as exercises } \\
\text { and self-assessment test before explanation. }\end{array}$ \\
\hline Sequential & $\begin{array}{l}\text { - Small chunks of information, with 'forward' } \\
\text { and 'backward' navigation ability, } \\
\text { - } \quad \text { No hyperlinks within text. }\end{array}$ \\
\hline Global & $\begin{array}{l}\text { - Table of contents, Summary, and Overview } \\
\text { of information, } \\
\text { - } \quad \text { Random jumps through hyperlinks for more } \\
\text { information. }\end{array}$ \\
\hline
\end{tabular}

SeLA accommodated the three dimensions of FSLSM as follows:

- Visual/Verbal: This dimension determines the presentation of learning objects and uses the metadata attribute that is called "Format". In general, the selection will be as the following:

o For Visual Student: SeLA selects the visual and pictorial learning objects.

o For Verbal Student: SeLA selects the textual or audio learning objects.

- Global/Sequential: This dimension affects both the selection and the sequencing of learning objects. Figure 6 shows the general structure of the course for both global and sequential students.

- Sensing/Intuitive: This dimension affects both the selection and the sequencing of learning objects. The general structure of the course for both sensing and intuitive is clarified in Figure 7. 


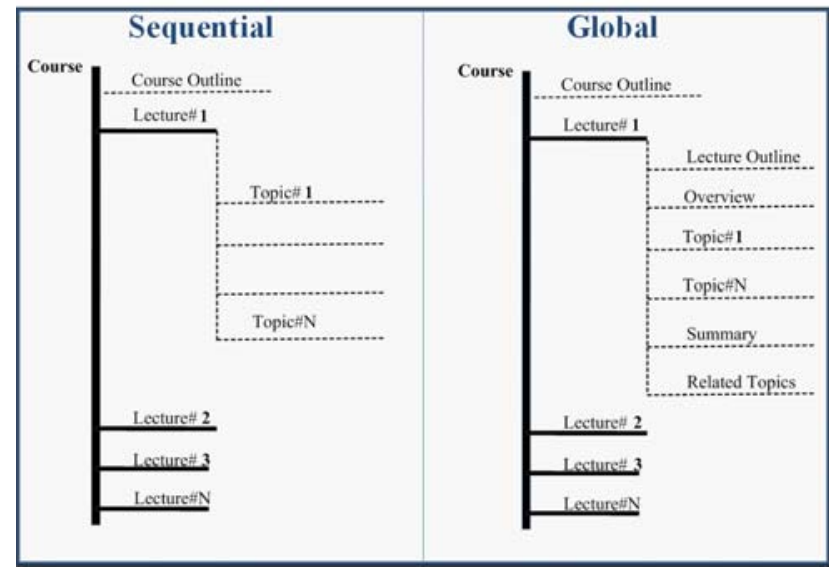

Figure 6. Course Framework for Sequential and Global Students

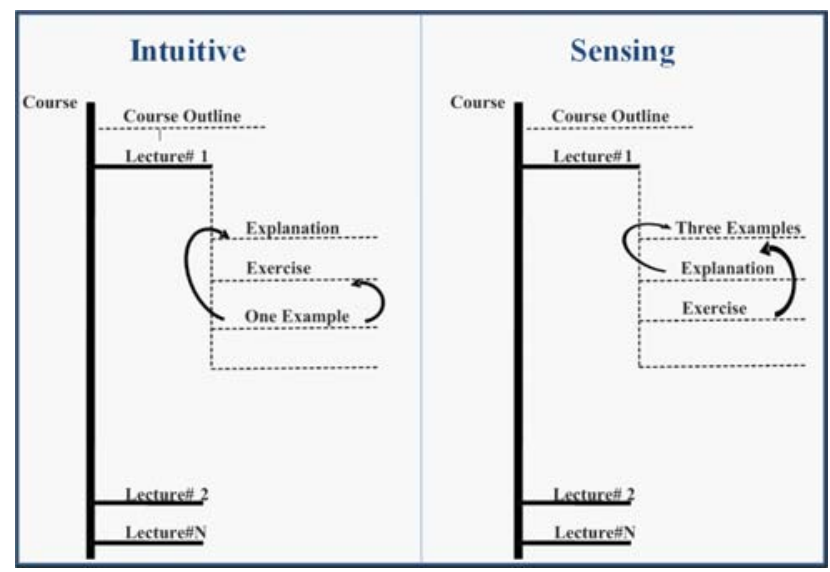

Figure 7. Course Framework for Intuitive and Sensing Students

\section{Prototype Design and Implementation}

The high-level architecture (as shown in Figure 8) is composed of two main engines: Authoring and Delivery engines.
The first one consists of two components: the knowledge Base Builder and the Course Preparation Engine. This research distinguishes between an Author, who builds the knowledge base for a certain knowledge area, and an Instructor, who uses the ready knowledge base in his/her domain and adjust it to his/her learning objectives.

\subsection{SeLA Knowledge Base Builder}

The Author, who is assumed to be an expert in specific domain, is expected to create the Course Ontology for a given domain knowledge with the help of the Concept Structure Editor which visualizes the nodes and the relationships between them. In the prototype, the author can visually define concepts and the relations among these concepts. However, some of the concept relationships, such as has part and follow relationships, can be deduced directly from the concepts structure, while others, such as prerequisite and related relationships, are assumed to be provided by the author using Concept Relations. Also, the learning objects are described by the author, when he/she uploads a new LO using $L O$ Editor. LOR contains the learning objects and their metadata.

\subsection{SeLA Course Preparation}

The instructor can create his/her own course using Course Structure Editor. It enables defining courses, lectures and other requirements. Learning Objective Editor allows instructor to define their objectives by providing them with all the concepts for the selected domain and all the keywords for RBT.

\subsection{Delivery Engine}

The Delivery engine is responsible for providing adaptive courses for each individual student according to his/her model.

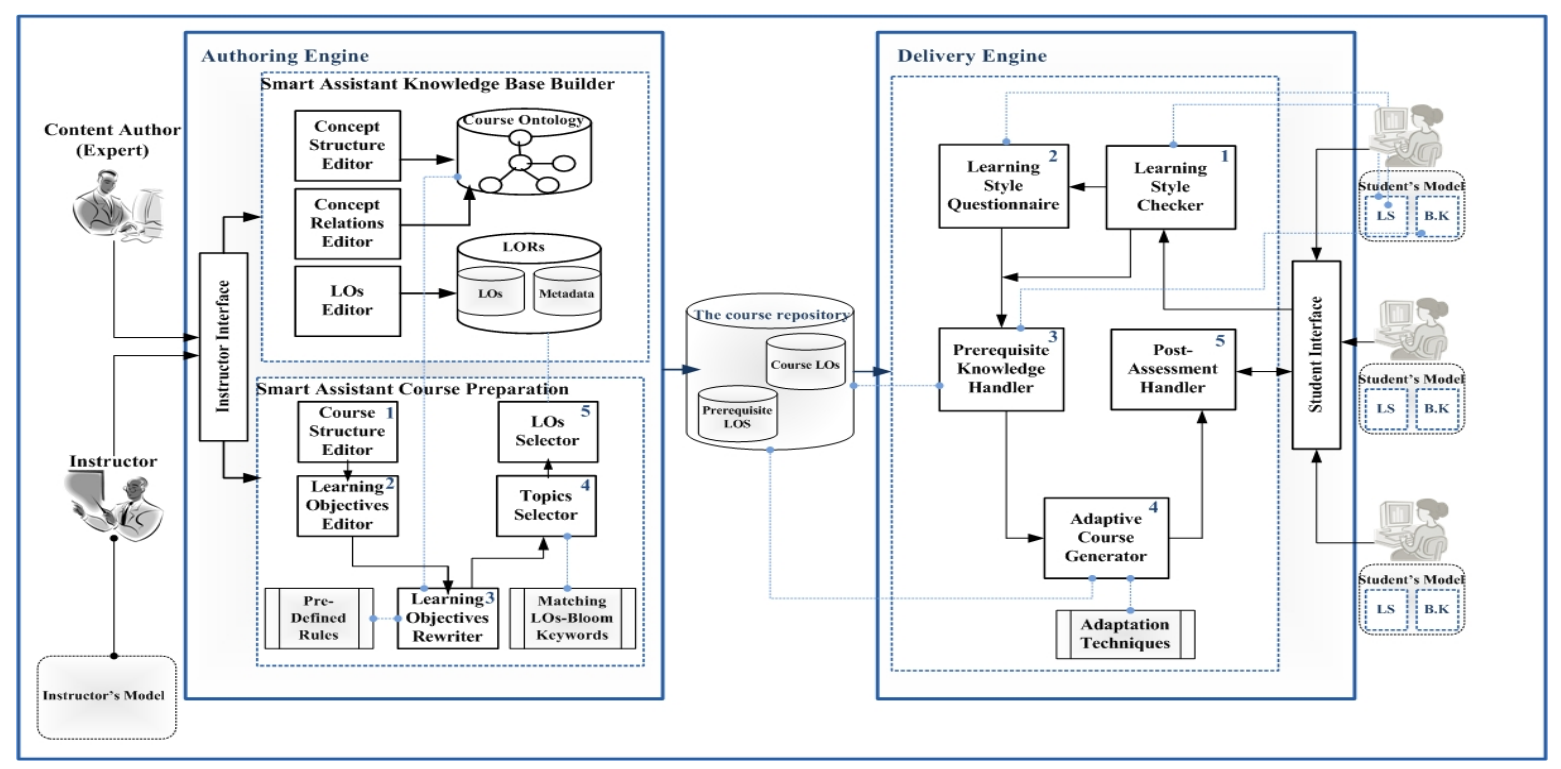

Figure 8. SeLA’s High-Level Architecture 
When the student login to the SeLA, Learning Style Checker component checks if he/she had access to the system before and had a preferred learning style in his/her model. If the student had a preferred learning style, this component will retrieve it and moves the control to Prerequisite Knowledge Handler. If the student does not have a preferred learning style, the Learning Style Questionnaire will be activated to the student.

In order to validate our approach, we implemented a course module in the domain of Artificial Intelligence specifically Depth first search and Breadth first search as uninformed search strategies. Our prototype is a Microsoft .NET application developed in Visual Basic (VB) and Active Server Pages (ASP), which allows the dynamic generation of pages with Visual Studio 2005 and executed on a Windows XP/Vista platform.

\section{Evaluation}

First of all, we want to make it clear that we are only employing educational methods and psychological theories that belong to specialized scientists. Our work does not involve by any means in proving or verifying any of those theories and methods, but rather only utilizing them. If any of them showed to be incorrect or inaccurate, then it is the sole responsibility of its owner. This section discusses the evaluation of the model and its results. The evaluation part of this work is divided into two parts: authoring and delivery with the prototype.

\subsection{Evaluation of the Authoring Model}

This section discusses the evaluation method of the authoring model including the rewriting rules, the extraction of the detailed syllabus, and the selection of appropriate learning materials.

We have collected a number of syllabuses that teach Artificial Intelligence courses. These syllabuses were available online at various universities. We have taken the learning objectives of these courses and brought them into the system. Then, we compared the produced syllabus and learning materials suggested by Smart E-Learning Assistant with these available in the original course syllabuses. Figure 9 gives an overview of this evaluation method.

This evaluation method is applied on two examples for the purpose of:

- Verifying the model,

- Tuning up the model for correctness and comprehensiveness,

- Identifying those places of the critical parts of the model that impact the results.

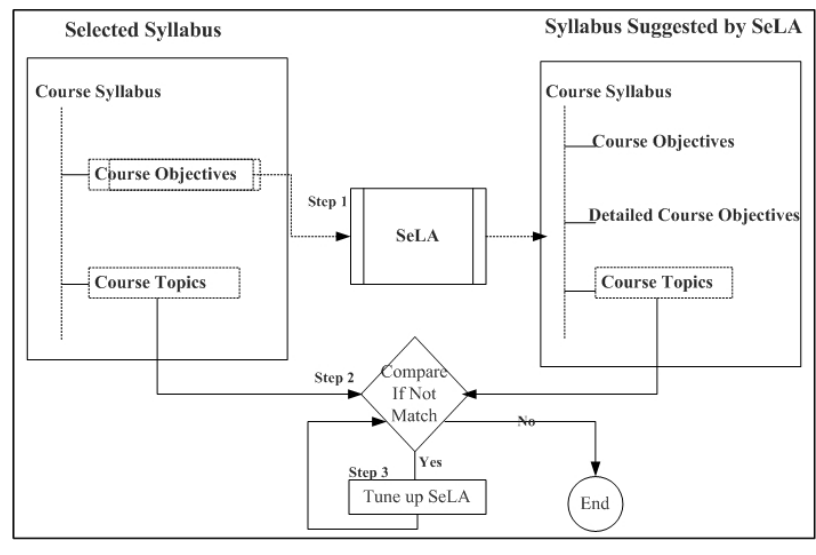

Figure 9. Evaluation Method of the Authoring Stage

\subsection{Evaluation of the Delivery Model}

One of the methods followed in evaluating SeLA was an experiment in which three groups of uniformly distributed students were formed according to Graf's study [7]. The whole sample was of 30 volunteered students of the third year mainly from the Females Campus of the Information Technology Department at King AbdulAziz University who did not study any "Artificial Intelligence" Courses. The students are distributed to the three groups randomly such that their GPAs are uniformly distributed across the groups to become probabilistically equivalent.

The online lecture consisted of two subjects - depth and breadth first search strategies explaining theoretical and practical parts as well as examples. When students registered in SeLA, they were asked to fill in a student model assessment questionnaire. Students belonging to the first group (referred to as matched group) were presented with a course that matched their learning styles. The second group (referred to as mismatched group) got a course that mismatched their learning styles. The third group (referred to as control group) was provided with a course where all available learning objects were presented in a default sequence independent of the students' learning styles. After studying the material with SeLA, students were given a post-test for assessing their learning outcomes and performance.

Table 4 shows the mean (M) and the standard deviation (SD) of each group for both the post-test marks and the time spent in studying the material (open time was given for each individual student to finish the given material).

Analyzing the obtained results, a conclusion can be drawn as follows:

- Because an open time was given for each student for perfectly studying the presented material, the average of the post-test scores for the three groups was close, but the average time spent was highly different. This neutralizes the effectiveness factor of the evaluation and focuses more on the efficiency. 
- Students of the matched group spent the least average time in the course, which confirms the hypothesis that using adapted learning material that matches the individual learning style would make learning more efficient. In addition, the low standard deviation for the matched group as compared to the other two groups would be analyzed in favor of the presented material rather than the individual skills.

- However, analyzing the standard deviation of the post-test marks revealed that the dispersion for the matched group was the least indicating that adapting the material made weaker students achieve similarly to those stronger ones. On the other hand, the higher standard deviation of the post-test marks for the other two groups reveals a significant difference between the sample students indicating that those few highscore students (having strong individual skills) had unfairly affected the value of the mean, which still argues for the improved effectiveness of the learning process due to adapting the learning material regardless of the individual skills.

Table 4. Mean and Standard Deviation of the Post-test Marks and the Study Time of all Groups

\begin{tabular}{|l|c|c|c|c|c|c|}
\hline & \multicolumn{2}{|c|}{$\begin{array}{c}\text { Matched } \\
\text { Group }\end{array}$} & \multicolumn{2}{c|}{$\begin{array}{c}\text { Mismatched } \\
\text { Group }\end{array}$} & \multicolumn{2}{c|}{$\begin{array}{c}\text { Control } \\
\text { Group }\end{array}$} \\
\cline { 2 - 7 } & M & SD & M & SD & M & SD \\
\hline $\begin{array}{l}\text { Time spent to study } \\
\text { the course (in } \\
\text { minutes) }\end{array}$ & 18 & 5.37 & 30 & 6.24 & 27 & 11 \\
\hline $\begin{array}{l}\text { Score of the post-test } \\
(10 \text { marks) }\end{array}$ & 8.8 & 1.62 & 7.30 & 3.68 & 8.75 & 3 \\
\hline
\end{tabular}

In summary, the experiment proved that away of the individual skills, adapting the learning material to match each individual student's learning style would overcome the deficient student's skills in favor of improving both the effectiveness and efficiency of the learning process for each individual student.

\section{Conclusion}

The main contribution in this research is leveraging learning materials reuse augmented with adaptability to assist both instructors, who design and teach a course, and students, who are the course recipients; for the sake of improving both the efficiency and effectiveness of the learning process.

In this research, a model of Smart e-Learning Assistant (SeLA) has been developed which consists of two main components: Smart Instructor Assistant (SIA) and Smart e-Tutor (ST). It utilizes two main theories: Revised Bloom's Taxonomy (RBT) in SIA for shaping the course syllabus and Felder \& Silverman Learning Style Model (FSLSM) in ST for shaping and adapting the delivered material to match the preference style for each individual student.
A new mechanism for rewriting high-level objectives has been developed to formalize the final course objectives (instructional objectives) into a course syllabus following the model introduced by RBT. An adapted ontology that accommodates RBT is specially designed for that purpose, in which the prerequisite relation is augmented with three of the six Bloom's levels.

On the other hand, LOs description is also adapted by introducing a new categorization to accommodate the same three levels of RBT-namely, remembering, understanding, and applying LOs. In addition, new additional metadata attributes for LOs are suggested, which are Bloom's level, content type, and teaching strategy which aid in selecting the proper LOs at delivery time to suit each specific student.

SeLA's model has been tested and evaluated including its two parts; authoring and delivery. For the purpose of this evaluation, a prototype has been designed and implemented in .NET environment as a proof of concept. This prototype is used as a main constituent for experiments in which a collection of learning objects, in the domain of Artificial Intelligence, have been created, tagged, and added to SeLA's knowledgebase, a lecture is composed, to which target sample students are exposed. The results of the experiment were promising.

However, researchers recognize that many areas are yet require further exploration. A good starting point for future work involves extending the learning objects repository to accommodate more LOs, and hence, extending the ontology to cover more concepts and topics.

In addition, more attributes for the instructor's model are envisioned, such as preferred teaching strategies and preferred teaching style. These extra attributes require investigating their impact on SeLA's model. Yet another emerging extension in SeLA's model might be in accommodating more attributes when stating the course objectives, such as student competency and audience categorization. Extending the student model with more attributes, such as cognitive traits, motivation and skills, still needs further investigation.

\section{References}

[1] B. S. Bloom, Taxonomy of educational objectives: The classification of educational goals: Handbook1, cognitive domain (New York, Toronto, Longmans, Green, 1956).

[2] L. Anderson \& D. E. Krathwohl, A Taxonomy for learning teaching and assessing: A revision of Bloom's taxonomy of educational objectives (New York: Addison Wesley Longman, Inc, 2001). 
[3] R. M. Felder, Reaching the Second Tier: Learning and Teaching Styles in College Science Education, Journal of College Science Teaching, 23 (5), 1993, 286-290.

[4] R.M. Felder \& L.K. Silverman, Learning and Teaching Styles in Engineering Education, Engineering Education, 2002, Vol. 78, No. 7, pp. 674-681.

[5] D. Kolb, Experiential learning (Englewood Cliffs, NJ: Prentice-Hall, 1998).

[6] I. B. Myers, M. H. McCaulley, N. L. Quenk, \& A. L. Hammer, MBTI ${ }^{\circledR}$ Manual: A guide to the development and use of the Myers-Briggs Type Indicator, 3rd. ed ( Palo Alto, CA: CPP , 1998).

[7] S. Graf, Kinshuk, \& G. Kappel, Adaptivity in Learning Management Systems Focussing on Learning Styles , Ph.D. Thesis, Faculty of Informatics , Vienna University of Technology, 2007.

[8] S. Gamalel-Din, \& R. AlOtaibi, Smart Assistant for Adaptive Course Preparation and Delivery in E-Learning Environments. In the Proceedings of the 7th European Conference on e-Learning, pp 390-401, ISSN: 978-1906638-23-1, 2008.

[9] A. Nussbaumer, C. Gütl, \& D. Albert, Supporting Technology-enhanced Learning through Semi-automatic Detection and Management of Skill and Competence Structures. In the Proceedings of the 10th International Conference on Interactive Computer aided Learning, 26 28 September 2007, Villach, Austria.
[10] A. Zouaq, R. Nkambou, \& C. Frasson, An Integrated Approach for Automatic Aggregation of Learning Knowledge Objects, Interdisciplinary Journal of Knowledge and Learning Objects (IJKLO), 3: 135-162, 2007.

[11] E. Popescu, C. Badica, \& P. Trigano, Learning Objects' Architecture and Indexing in WELSA Adaptive Educational System, Scalable Computing: Practice and Experience, Vol. 9(1), pp. 11-20, ISSN: 1895-1767, 2008.

[12] S. Graf, \& K. Kinshuk, Providing Adaptive Courses in Learning Management Systems with Respect to Learning Styles. In the Proceedings of World Conference on E-Learning in Corporate, Government, Healthcare, and Higher Education, AACE, 2007, pp. 2576-2583.

[13] H.J. Cha, Y.S. Kim, J.H. Lee, \& T.B. Yoon, An Adaptive Learning System with Learning Style Diagnosis based on Interface Behaviors. Workshop Proceedings of Int'l. Conf. E-learning and Games (Edutainment), Hangzhou, 2006

[14] P. Paredes, \& P. Rodriguez, A mixed approach to modeling learning styles in adaptive educational hypermedia. In the Proceedings of the Third IASTED Conference on Web-Based Education (WBE2004), (Innsbruck, Austria, 2004).

[15] N. Bajraktarevic, W. Hall, \& P. Fullick, Incorporating Learning Styles in Hypermedia Environment: Empirical Evaluation. In the Proceedings of the Workshop on Adaptive Hypermedia and Adaptive Web-Based Systems, Nottingham, UK, 2003, pp. 41-52. 